\title{
Pattern of Physical Activity and Sedentary Behavior in Early Childhood
}

\author{
Adang Suherman, Nur Indri Rahayu*, Jajat, Mohammad Zaky \\ Faculty of Sport and Health Education, Universitas Pendidikan Indonesia, Bandung, Indonesia
}

Received April 23, 2021; Revised July 12, 2021; Accepted July 22, 2021

\section{Cite This Paper in the following Citation Styles}

(a): [1] Adang Suherman, Nur Indri Rahayu, J Jajat, Mohammad Zaky, "Pattern of Physical Activity and Sedentary Behavior in Early Childhood," International Journal of Human Movement and Sports Sciences, Vol. 9, No. 4A, pp. 125 - 129, 2021. DOI: 10.13189/saj.2021.091321.

(b): Adang Suherman, Nur Indri Rahayu, J Jajat, Mohammad Zaky (2021). Pattern of Physical Activity and Sedentary Behavior in Early Childhood. International Journal of Human Movement and Sports Sciences, 9(4A), 125 - 129. DOI: 10.13189/saj.2021.091321.

Copyright $(\mathrm{O} 2021$ by authors, all rights reserved. Authors agree that this article remains permanently open access under the terms of the Creative Commons Attribution License 4.0 International License

\begin{abstract}
The research aimed to examine the prevalence and comparisons between physical activity and sedentary behavior of early-year children in preschool. The samples were 55 early-year children under five years old whose parents were willing to become participants voluntarily. Considering that the children have a plasticity characteristic, it is possible to form movement and healthy behavior from this early stage. Twenty-four-hour movement behaviors (physical activity, sedentary time, and sleep) were assessed using the $\mathrm{ActiGraph}^{\mathrm{TM}}$ accelerometer. Compared to early childhood children in a rural area, the results showed that early childhood children in urban areas were more physically active and spent less time on sedentary behavior $(\mathrm{p}<0.05)$. Overall, there were no physical activities or sedentary behavior differences based on gender $(p>0.05)$. Meanwhile, male children in the rural area spent less physical activity and were more sedentary than male children in the urban area $(p<0.05)$. There was no difference in both physical activity and sedentary behavior $(p>0.05)$. These findings suggest that interventions aiming to improve physical activity and reduce sedentary behavior in early childhood may be more effective by considering the residential location.
\end{abstract}

Keywords Early Childhood, Physical Activity, Sedentary Behavior

\section{Introduction}

The benefit of regular physical activity has been widely studied. Much evidence shows that regular physical activity and exercise increase health and functional capacity and reduce the risk factors of chronic diseases, such as coronary heart disease, hypertension, obesity, and cardiovascular [1-3]. The early years (defined as 0-5 years) are arguably the most critical period in developing important physical, motor, social, and cognitive skills. As a sensitive period of brain development, it provides a window of opportunity where developmental plasticity can be exploited to positively influence a child's life trajectory in each of the above developmental areas and reduce health inequalities [4]. Considering a young child physical and motor developments, in the context of how they move throughout a typical day, it is usually a combination of sleep, sitting, standing, and different intensities of physical activity, mostly in the form of play and other daily living activities. The shortage of information is more pronounced in low and middleincome countries (LMICs), many of which are in rapid urbanization, which may further impact the healthy development of these behaviors among this age group. The World Health Organization (WHO) has identified the prevention of obesity in young children as one of its key priorities for the 21st Century1, where movement behaviors play a key role in contributing to this condition. However, currently, there are no international movementrelated guidelines for the early years. This was a specific recommendation from the WHO Report of the Commission on Ending Childhood Obesity [5]. It is 
problematic for many countries, especially LMICs, where awareness of the importance of healthy levels of these behaviors in the early years is low and benchmarks to determine their prevalence are lacking.

Several countries, such as Australia, Canada, New Zealand, and the United Kingdom, have developed specific physical activity and screen-time guidelines for the early years. Initial data collected from Canada and Australia show that around $15 \%$ of preschoolers (age 3 and 4 years) meet all three of the daily movement guidelines: (i) at least 180 minutes of physical activity, of which at least 60 minutes of energetic play, (ii) no more than 1 hour of sedentary screen time, and (iii) 10 to 13 hours of good quality sleep [6,7]. This increases their risk for poorer health and developmental outcomes [8-10] and potentially poorer human capital development [11]. For these reasons, it is important and timely to collect international surveillance data using the new global 24-hr integrated movement guidelines as benchmarks in a range of countries.

Physical activity, aerobic activities, and bonestrengthening are essential to building physical fitness. Those activities should each be incorporated at least three $\mathrm{d} / \mathrm{wk}$. The average weekly frequency of VPA is $\geq 3$, while the average weekly frequency of muscle and bonestrengthening activities is $\geq 3 \mathrm{~d}$. Evidence for a specific recommendation on duration lacks, so guidelines at present can only speak to frequency. Some assumptions state that sedentary behavior is negatively correlated with physical activity; one example is multimedia use, which causes children to be physically inactive $[12,13]$. However, this statement is still inconsistent because it is also reported that there is no significant relationship between watching TV and physical activity [14]. Research conducted in Singapore shows that increased use of information and communication technology does not have a negative impact on physical activity [12]. Some research defines that technology and multimedia use belong to sedentary behavior, but a broader measurement is needed regarding other sedentary behavior types. Research about Canadian 24-Hour Movement Guidelines for Children and Youth shows an integration of physical activity, sedentary behavior, and sleep. Four systematic reviews (physical activity, sedentary behavior, sleep, integrated behaviors) examining the relationships between and among movement behaviors and several health indicators were completed and interpreted by expert consensus. Following an introductory preamble, the guidelines provide evidence-informed recommendations for a healthy day ( 24 h) and comprise a combination of sleep, sedentary behaviors, light-, moderate-, and vigorous-intensity physical activity [15]. Another research relevant to this research is Adherence to 24-Hour Movement Guidelines for the Early Years and associations with social-cognitive development among Australian preschool children. The result of children screen time and sleep, reported by parents, shows that $14.9 \%$ of children met all three guidelines[6]

The research aimed to examine the prevalence and comparisons between physical activity and sedentary behavior of early childhood in preschool. In addition, the aim was to create a global support network among investigators throughout these countries. The countries that have been chosen were geographically and culturally diverse and represented a broad range of Human Developmental Indexes (HDIs). For many LMICs, this would be the first time surveillance data on these behaviors had been collected. A primary knowledgetranslation product would be in the form of an Early Years Physical and Motor Development Report Card, similar to the 38 Physical Activity Report Cards for Children and Youth released by the Active Healthy Kids Global Alliance (AHKGA) in 2016 (one-third were LMICs). This would provide an opportunity to stratify across HDI levels and to examine differences in prevalence and patterns that can further inform policy, especially among countries undergoing rapid social and economic transition.

\section{Methods}

\section{Participants}

This study consisted of 55 children aged 4 years, 22 children from urban areas and 23 children from rural areas. Participants were recruited from 10 playgroups in West Java province. The initial stage before recruitment was to conduct a survey on these playgroups regarding the availability of children who meet the criteria in terms of age. Furthermore, socialization was carried out to schools and parents. The samples of the study were 55 early-year children under five years old taking part in this research. Their parents were willing to participate voluntarily. Before installing the instrument, parents received an explanation of the instrument installation procedure and filled in the informed consent as a sign of willingness to be involved in this study

\section{Data collection and procedure}

This research was conducted in early childhood who were members of 10 playgroups located in West Java Province which were included in rural and urban areas for approximately 8 months. The children were selected based on two criteria, including that the child was 4 years old and approved by their parents. Children and parents participated voluntarily in this study and had given their consent. Data collection was carried out at school and at home. The children were fitted with a device called the Accelerometer actigraph at school. They had to continue to use this tool for a 3 day period and continue to use it as long as they were at home. After 3 days, the measuring 
device was released and the researcher did it in school. Data were taken in the form of early childhood physical activity patterns for 24 hours with parental supervision. Children were asked to wear an accelerometer continuously (including sleeping) for a minimum of three days. Parents/carers reported their child's use of electronic media, sleep quality, and restrained sedentary time. Sociodemographic data were collected from parents/carers using a modified version of the WHO STEPS Survey. Before taking data, staff were trained in using accelerometers to measure movement behaviors in this age group.

\section{Measurements}

Data in the form of twenty-four-hour movement behaviors (physical activity, sedentary time, and sleep) were assessed by using an accelerometer ActiGraph GT3X. ActiGraph is a small electronic device that has been widely used by researchers in measuring physical activity and sedentary behavior. The ActiGraph GT3X accelerometer, is a small and lightweight triaxial accelerometer $(27 \mathrm{~g} ; 3.8 \mathrm{~cm} \times 3.7 \mathrm{~cm} \times 1.8 \mathrm{~cm})$ capable of recording acceleration in three axes (vertical, anteroposterior, and medio-lateral). In addition, the modified WHO STEPS Survey was also used as an instrument for collecting sociodemographic data.

\section{Data analysis}

The statistical analysis of the independent sample t-test was used to test the differences between the two group samples.

\section{Results}

This study involved 55 early childhood children aged under five years who came from rural and urban areas. As shown in Table 1, physical activity between rural and urban early childhood is significantly different $(p<0.05)$. Early childhood in urban areas was more physically active than those who lived in rural areas. Based on the MET's average, early childhood in urban areas was included at a moderate physical activity level. In contrast, those living in rural areas fell into the low physical activity category. In line with physical activity, early childhood sedentary behavior in urban areas was significantly different from rural areas $(p<0.05)$. Early childhood in rural areas spent more time on sedentary behavior (sitting \& lying) than urban children. Early childhood in urban areas spent 10 hours on sedentary behavior, while children in rural areas spent nearly 14 hours a day.

Table 1. Physical activity and sedentary behavior in early childhood

\begin{tabular}{|c|c|c|c|}
\hline Objectively Measures PA \& SB & & $\mathbf{M} \pm \mathbf{S D}$ & P Values \\
\hline \multicolumn{4}{|l|}{ Daily MET's Physical Activity } \\
\hline $\operatorname{Urban}(\mathrm{n}=22)$ & & $4.48 \pm 1.26$ & \multirow{2}{*}{0.000} \\
\hline Rural (n=23) & & $2.86 \pm 1.46$ & \\
\hline Males $(n=23)$ & & $3.77 \pm 1.78$ & \multirow{2}{*}{0.606} \\
\hline Females $(\mathrm{n}=22)$ & & $3.52 \pm 1.38$ & \\
\hline \multicolumn{4}{|l|}{ Sedentary Behavior (Hours) } \\
\hline Urban $(\mathrm{n}=22)$ & & $10.07 \pm 1.75$ & \multirow{2}{*}{0.001} \\
\hline Rural $(n=23)$ & & $13.93 \pm 5.00$ & \\
\hline Males $(n=23)$ & & $12.30 \pm 5.03$ & \multirow{2}{*}{0.678} \\
\hline Females $(\mathrm{n}=22)$ & & $11.77 \pm 3.27$ & \\
\hline Objectively Measures PA \& SB & $\mathbf{M} \pm \mathbf{S D}$ & \multicolumn{2}{|r|}{ P Values } \\
\hline \multicolumn{4}{|l|}{ Daily MET's Physical Activity } \\
\hline Male Urban $(\mathrm{n}=13)$ & $4.83 \pm 1.05$ & \multirow{2}{*}{\multicolumn{2}{|c|}{0.000}} \\
\hline Male Rural $(n=10)$ & $2.40 \pm 1.59$ & & \\
\hline Female Urban $(n=9)$ & $3.98 \pm 1.42$ & \multirow{2}{*}{\multicolumn{2}{|c|}{0.205}} \\
\hline Female Rural $(n=13)$ & $3.21 \pm 1.30$ & & \\
\hline \multicolumn{4}{|l|}{ Sedentary Behavior (Hours) } \\
\hline Male Urban $(n=13)$ & $9.45 \pm 0.98$ & \multirow{2}{*}{\multicolumn{2}{|c|}{0.006}} \\
\hline Male Rural $(\mathrm{n}=10)$ & $16.01 \pm 5.78$ & & \\
\hline Female Urban $(n=9)$ & $10.96 \pm 2.26$ & \multirow{2}{*}{\multicolumn{2}{|c|}{0.343}} \\
\hline Female Rural $(n=13)$ & $12.34 \pm 3.80$ & & \\
\hline
\end{tabular}


Overall, physical activity and sedentary behavior based on gender in early childhood were not significantly different $(p>0.05)$. However, the MET's of males was slightly higher on average than females. In addition, in line with physical activity, the average sedentary behavior of males was slightly higher than females.

Table 2 shows that there is a significant difference in physical activity between early childhood boys in urban and rural areas $(\mathrm{p}<0.001)$, as well as sedentary behavior $(p<0.05)$. Male children who lived in urban areas were more active than those in rural areas. Meanwhile, male children in rural areas spent more time on sedentary behavior than male children in urban areas. In contrast to the male group, female children physical activity and sedentary behavior did not differ between those who lived in urban and rural areas ( $p>0.05)$. Thus, female children who lived in rural and urban areas were relatively the same in doing physical activity and sedentary behavior.

\section{Discussions}

This study examined physical activity and sedentary behavior in early childhood children who lived in urban and rural areas. The results showed a difference in physical activity and sedentary behavior between early childhood in rural and urban areas. Overall, there were no differences in physical activity and sedentary behavior according to gender. However, early childhood children who lived in urban areas were more physically active, while male children who lived in rural areas spent more time in sedentary behavior. Meanwhile, physical activity and sedentary behavior in female children were relatively the same.

\section{Urban-rural physical activity}

Children in urban areas were more physically active than children in rural areas, especially male children. These results align with previous studies, which reveal that children living in rural areas are less physically active than those who live in urban areas [16]. Previous research on children aged 2 - 11 years reveals that children living in rural areas report higher physical activity than those in urban areas [17]. The difference in this study results is predicted to be influenced by different cultural factors in each country. As revealed in research on physical activity, environment and culture factors are factors identified to influence physical activity participation [17]. There are difficulties in comparing different results in various countries, one determining rural and urban criteria [18].

\section{Urban-rural sedentary behavior}

Early childhood children in rural areas spent more time on sedentary behavior than those who lived in urban areas, especially male children. This result is in line with previous research, which also reveals that children of all genders who live in urban areas spend less time on sedentary activities than children in rural areas [19]. In America, young people in rural areas spend more time watching TV and computers than in urban areas [20]. Unfortunately, previous studies comparing physical activity and sedentary behavior in early childhood based on residence place are relatively limited, so it is not easy to compare more specifically.

\section{Gender and physical activity}

Overall, physical activity in early childhood did not differ based on gender. The next result found differences in rural-urban physical activity for males, but not for females. Previous research related to differences in physical activity based on gender in early childhood under five years has been relatively limited [21]. It is in contrast to studies at other age levels, which relatively have more research results. One of the studies found in elementary school-age children, grades $1-6$, states that boys are more active than girls [22]. Although gender is one of the factors closely related to physical activity in preschool children [23], other factors, such as environment, are also predicted to influence physical activity behavior. In another study, it was stated that girls in rural areas were more interested in increasing physical activity than boys [24]. These findings can be a preliminary description for further research with a larger sample scale and studying other variables, such as parental background.

\section{Conclusion}

This study concludes that early childhood children in urban areas are more physically active and spend less time on sedentary behavior than children in rural areas. Place of residence (rural-urban) is predicted to be the strongest variable compared to gender on children physical activity and sedentary behavior in early childhood. Except for male children in rural areas, all groups were in the moderate physical activity category.

\section{Acknowledgment}

This paper and the research behind it would not have been possible without the exceptional support of LPPM UPI, FPOK UPI, and the research team.

\section{REFERENCES}

[1] Bouchard CE, Shephard RJ, Stephens TE. Physical activity, fitness, and health: international proceedings and consensus statement. In: International Consensus 
Symposium on Physical Activity, Fitness, and Health, 2nd, May, 1992, Toronto, ON, Canada. Human Kinetics Publishers; 1994.

[2] Pate RR, Pratt M, Blair SN, Haskell WL, Macera CA, Bouchard C, et al. Physical activity and public health: a recommendation from the Centers for Disease Control and Prevention and the American College of Sports Medicine. Jama. 1995;273(5):402-7.

[3] Hill JO, Leon AS. Physical activity and cardiovascular health: A National Consensus. 1997;

[4] Fuhrmann D, Knoll LJ, Blakemore SJ. Adolescence as a Sensitive Period of Brain Development. Trends Cogn Sci [Internet]. 2015;19(10):558-66. Available from: http://dx.doi.org/10.1016/j.tics.2015.07.008

[5] World Health Organization. Report of the commission on ending childhood obesity. World Health Organization; 2016.

[6] Cliff DP, McNeill J, Vella SA, Howard SJ, Santos R, Batterham M, et al. Adherence to 24-hour movement guidelines for the early years and associations with socialcognitive development among Australian preschool children. BMC Public Health. 2017;17(5):857.

[7] Chaput J-P, Colley RC, Aubert S, Carson V, Janssen I, Roberts KC, et al. Proportion of preschool-aged children meeting the Canadian 24-Hour Movement Guidelines and associations with adiposity: results from the Canadian Health Measures Survey. BMC Public Health. 2017;17(5):147-54.

[8] Poitras VJ, Gray CE, Janssen X, Aubert S, Carson V, Faulkner G, et al. Systematic review of the relationships between sedentary behaviour and health indicators in the early years (0-4 years). BMC Public Health. 2017;17(Suppl 5).

[9] Chaput J-P, Gray CE, Poitras VJ, Carson V, Gruber R, Birken CS, et al. Systematic review of the relationships between sleep duration and health indicators in the early years (0-4 years). BMC Public Health. 2017;17(5):855.

[10] Kuzik N, Poitras VJ, Tremblay MS, Lee E-Y, Hunter S, Carson V. Systematic review of the relationships between combinations of movement behaviours and health indicators in the early years $(0-4$ years $)$. BMC Public Health. 2017;17(5):849.

[11] Black MM, Walker SP, Fernald LCH, Andersen CT, DiGirolamo AM, Lu C, et al. Early childhood development coming of age: science through the life course. Lancet. 2017;389(10064):77-90.

[12] Chia M, Wang J, Miang TS, Jong QJ, Gosian KK. Relationships between Hours of Computer Use, Physical Activity and Physical Fitness among Children and Adolescents. Eur J Phys Educ. 2002;7(2):136-55.

[13] Vandewater EA, Shim MS, Caplovitz AG. Linking obesity and activity level with children's television and video game use. J Adolesc. 2004;

[14] McGuire MT, Neumark-Sztainer DR, Story M. Correlates of time spent in physical activity and television viewing in a multi-racial sample of adolescents. Pediatr Exerc Sci. 2002 ;

[15] Tremblay MS, Chaput JP, Adamo KB, Aubert S, Barnes JD, Choquette L, et al. Canadian 24-Hour Movement Guidelines for the Early Years (0-4 years): An Integration of Physical Activity, Sedentary Behaviour, and Sleep. BMC Public Health. 2017;

[16] Al-Nuaim AA, Al-Nakeeb Y, Lyons M, Al-Hazzaa HM, Nevill A, Collins P, et al. The prevalence of physical activity and sedentary behaviours relative to obesity among adolescents from Al-ahsa, Saudi Arabia: Rural versus urban variations. J Nutr Metab. 2012;2012.

[17] Liu JH, Jones SJ, Sun H, Probst JC, Merchant AT, Cavicchia P. Diet, physical activity, and sedentary behaviors as risk factors for childhood obesity: An urban and rural comparison. Child Obes. 2012;8(5):440-8.

[18] Wilbur JE, Chandler P, Dancy B, Choi JW, Plonczynski D. Environmental, policy, and cultural factors related to physical activity in urban, African American women. Women Heal. 2002;36(2):17-28.

[19] Machado-Rodrigues AM, Coelho-E-Silva MJ, Mota J, Padez C, Martins RA, Cumming SP, et al. Urban-rural contrasts in fitness, physical activity, and sedentary behaviour in adolescents. Health Promot Int. 2014;29(1):118-29.

[20] Carson V, Iannotti RJ, Pickett W, Janssen I. Urban and rural differences in sedentary behavior among American and Canadian youth. Heal Place [Internet]. 2011;17(4):920-8. Available from: http://dx.doi.org/10.10 16/j.healthplace.2011.04.007

[21] Sääkslahti A, Numminen $P$, Varstala V, Helenius H, Tammi A, Viikari J, et al. Physical activity as a preventive measure for coronary heart disease risk factors in early childhood. Scand J Med Sci Sport. 2004;

[22] Trost SG, Pate RR, Sallis JF, Freedson PS, Taylor WC, Dowda M, et al. Age and gender differences in objectively measured physical activity in youth. Med Sci Sports Exerc. 2002;34(2):350-5.

[23] Finn K, Johannsen N, Specker B. Factors associated with physical activity in preschool children. J Pediatr. 2002;140(1):81-5.

[24] Amiri P, Naseri P, Vahedi-Notash G, Jalali-Farahani S, Mehrabi Y, Hamzavi-Zarghani N, et al. Trends of low physical activity among Iranian adolescents across urban and rural areas during 2006-2011. Sci Rep [Internet]. 2020;10(1):1-7. Available from: https://doi.org/10.1038/s4 1598-020-78048-0 